\title{
Anti-Inflammatory Potential of Some Essential Oils: A Review Ritika Kushwah ${ }^{*}$, M. K. Gupta² \\ ${ }^{1}$ Research Scholar, Department of Pharmacy, Oriental College of Pharmacy and Research, Indore 2Dean and Professor, Department of Pharmacy, Oriental college of Pharmacy and Research, Indore
}

\begin{abstract}
A B S T R A C T
Inflammation and pain are common phenomena associated with a number of diseases. Inflammatory diseases result from the body's response to tissue damage, and if the resolution is not adequate or the stimulus persists, there will be progression from acute inflammation to chronic inflammation, leading to the development of cancer and neurodegenerative and autoimmune diseases. It is necessary to search for new biologically active compounds with anti-inflammatory activity. Essential oils are complex mixtures isolated from aromatic plants which may possess antioxidant and anti-inflammatory activities. This article briefly summarizes the potential of essential oils and their compounds for the treatment of inflammatory diseases.
\end{abstract}

Keywords: Essential Oils; Anti-inflammatory; Antioxidant

A R T I C L E I N F O: Received 19 Sept. 2019; Review Completed 25 Nov. 2019; Accepted 06 Dec. 2019; Available online 15 Dec. 2019
Cite this article as: 19

\section{INTRODUCTION:}

I nflammation is characterized as a normal response to tissue damage caused by several potentially injurious stimuli, induced by biological, chemical, and physical factors. ${ }^{[1]}$ If the treatment of inflammation is inadequate or the stimulus persists, chronic inflammation occurs, predisposing the host to various diseases including cancer and neurodegenerative diseases. ${ }^{[2]}$ In recent years, the search for more effective drugs for the treatment of the inflammation with fewer side effects has encouraged researchers to study and develop new drugs. The search for natural products derived from plants is a promising reality, and among the substances with pharmacological potential we can mention the essential oils. ${ }^{[3] .}$ The objective of this review is to relate the use of essential oils correlating its anti-inflammatory effect in the treatment of inflammations.

\section{Essential Oil:}

An essential oil is defined internationally as the product obtained by hydrodistillation, steam distillation or dry distillation or by a suitable mechanical process without heating (for Citrus fruits) of a plant or some parts of it. ${ }^{[4]}$ They are aromatic oily liquids, volatile, characterized by a strong odour, rarely coloured, and generally with a lower density than that of water. ${ }^{[5]}$

All parts of aromatic plants may contain essential oils as follows:

- Flowers, of course, including: orange, pink, lavender, and the (clove) flower bud or (ylang-ylang) bracts,

- Leaves, most often, including: eucalyptus, mint, thyme, bay leaf, savory, sage, pine needles, and tree underground organs, e.g., roots (vetiver),

- Rhizomes (ginger, sweet flag),

- Seeds (carvi, coriander),

- Fruits, including: fennel, anise, Citrus epicarps,

- Wood and bark, including: cinnamon, sandalwood, rosewood. ${ }^{[6]}$ 


\section{List of Essential oils:}

Essential oils are derived from sections of plants

Table: 1 List of Essential oils

\begin{tabular}{|c|c|c|}
\hline S. No. & $\begin{array}{l}\text { Name of raw materials } \\
\text { of plants }\end{array}$ & Name of Essential Oils \\
\hline 1. & Bark & Cassia, Cinnamon, Sassafras \\
\hline 2 & Berries & Allspice, Juniper \\
\hline 3 & Flowers & $\begin{array}{l}\text { Cannabis, Clove } \\
\text { Jasmine, Lavender }\end{array}$ \\
\hline 4 & Leaves & $\begin{array}{l}\text { Cinnamon, Eucalyptus } \\
\text { Guava, Oregano } \\
\text { Tea tree, Wintergreen }\end{array}$ \\
\hline 5 & Peel & $\begin{array}{l}\text { Grapefruit, Lemon } \\
\text { Lime, Orange }\end{array}$ \\
\hline 6 & Resin & Frankincense, Labdanum \\
\hline 7 & Rhizome & Galangal, Ginger \\
\hline 8 & Roots & Valerian \\
\hline 9 & Seeds & $\begin{array}{l}\text { Celery, Cumin } \\
\text { Flax, Nutmeg oil } \\
\end{array}$ \\
\hline 10 & Woods & $\begin{array}{l}\text { Agar wood, Camphor } \\
\text { Sandalwood }\end{array}$ \\
\hline
\end{tabular}

\section{Production of Essential Oils by:}

- Distillation

- Expression
- Solvent extraction

- Florasols extraction

- Production quantities

\section{Essential Oils as Anti-Inflammatory Agents}

Inflammation is a normal protective response induced by tissue injury or infection and functions to combat invaders in the body and to remove dead or damaged host cells. The inflammatory response induces an increase of permeability of endothelial lining cells and influxes of blood leukocytes into the interstitium, oxidative burst, and release of cytokines. It also stimulates the activity of several enzymes as well as the arachidonic acid metabolism. Recently, essential oils have been used in clinical settings to treat inflammatory diseases such as rheumatism or arthritis. ${ }^{[7]} \mathrm{In}$ addition to the ability of some essential oils to scavenge free radicals, there is also evidence that some essential oils possess anti-inflammatory activity. For example, chamomile essential oil has been used for centuries as an anti-inflammatory and also for alleviating the symptoms associated with eczema, dermatitis and other pronounced irritation. ${ }^{[8]}$ However, there are other examples of essential oils (eucalyptus, rosemary, lavender, millefolia) along with other plants (pine, clove and myrrh) that have been used as mixed formulations as anti-inflammatory agents. ${ }^{[9]}$

Table 2: Anti-inflammatory activity of Essential oils.

\begin{tabular}{|l|l|l|l|}
\hline $\begin{array}{l}\text { S. } \\
\text { No. }\end{array}$ & Plant source & Main constituents & Biological activity \\
\hline 1 & Globba sessiliflora Sims. & $\beta$-Eudesmol, $($ E)- $\beta$-caryophyllene, caryophyllene oxide, T-muurolol & Anti-inflammatory \\
\hline 2 & Piper glabratum & $\beta$-Pinene, longiborneol, $\alpha$-pinene, $($ E)-caryophyllene & Anti-inflammatory \\
\hline 3 & hyllanthus muellerianus & Isoelemicinb, caryophyllene oxide, $\alpha$-Cadinol, 2 -isopropyl benzoic acid & Anti-inflammatory \\
\hline 4 & alvia officinalis & 1,8 -Cineole, camphor, $\beta$-pinene, E- $\beta$-caryophyllene & Anti-inflammatory \\
\hline 5 & Lippia gracilis Schauer & Thymol, carvacrol, $p$-cymene, $\alpha$-pinene & Anti-inflammatory \\
and healing activity \\
\hline 6 & Citrus limon & Limonene, $\beta$-pinene, $\gamma$-terpinene, sabinene & Anti-inflammatory \\
\hline 7 & Cymbopogon citratus & Geranial, neral, $\beta$-myrcene, geranyl acetate & Anti-inflammatory \\
\hline 8 & Anethum graveolens L. & $\alpha$-Phellandrene, limonene, dill ether, $\alpha$-pinene & Anti-inflammatory \\
\hline 9 & Citrus aurantium L. & Linalool, linalylacetate, nerolidol, $Z$,E-farnesol & Anti-inflammatory \\
\hline 10 & $\begin{array}{l}\text { Blumea balsamifera }(\mathrm{L} .) \\
\text { DC. }\end{array}$ & Borneol, caryophyllene, ledol, caryophyllene oxide & Anti-inflammatory \\
\hline
\end{tabular}

\section{Potential Beneficial Effects of Topical Application of Essential Oils on Skin}

\section{Olive Oil}

Olive oil comes from the fruits of Olea europaea trees. It consists mainly of oleic acid, with smaller quantities of other fatty acids such as linoleic acid and palmitic acid. More than 200 different chemical compounds have been detected in olive oil, including sterols, carotenoids, triterpenic alcohols, and phenolic compounds. The phenolic contents exhibit anti-inflammatory properties when olive oil is included in regular diet. ${ }^{[10]}$

\section{Eucalyptus oil}

Eucalyptus contain constituents like cineole (70\%-85\%), aromadendrene, limonene, terpinene, cymene, phellandrene and pinene. ${ }^{[11]}$ Eucalyptus oil has demonstrated its antioxidant, anti-inflammatory, anti-proliferative and antibacterial activities and researchers have proved its efficacy beyond doubt in treatment of various metabolic and infectious diseases. ${ }^{[12]}$ Treatment of rheumatoid arthritis, muscle and joint pains and aches is well reported from the essential oils of this plant. ${ }^{[13]}$ 


\section{Medicinal Benefits of Eucalyptus oil}

\section{Anti-inflammatory property ${ }^{[19][20]}$}

The species of Eucalyptus produced the effect that is the anti-inflammatory effect this demonstrates the rat paw induced edema by the carrageenan as well as dextran; the neutrophil is migrated into the peritoneal cavity this will induce the carrageenan as well as also induce the vascular permeability by using carrageenan and histamine. The result does not having the same consistency we were observed the some parameters that will be evaluated this will be evaluate in term of activities as well as dose dependent relationship. The oil and assay condition were used for the study. The data used for the oil extracts of EC,ET as well as EG that is possess central and peripheral effects this will neutrophildependent and independent anti-inflammatoryactivities.

\section{Lavender:}

Lavandula augustifolia essential oil and its major components, (-)-linalool and linalyl acetate, presented antiinflammatory properties in rats. ${ }^{[14]}$

Several studies have investigated the anti-inflammatory properties of compounds found in the lavender essential oil. These studies investigated the effects of different constituents of essential oils, such as $\alpha$ pipine, $\alpha$-terpinene, terpin-4-ol, $\alpha$-terpineol, linalyl acetate and linalool. These studies concluded that the compounds present in the lavender essential oil may have direct or indirect antiinflammatory or antinociceptive activities. ${ }^{[15]}$

\section{Clove oil:}

This essential oil obtained from Syzygium aromaticum. It is oil having analgesic, anti-inflammatory and as an antiseptic properties and used commonly in dental product due to eugenol.There are some important constituents that is present in clove are vanillin, crategolic acid, betacaryophyllene, eugenin, kaempferol, rhamnetinand the most important is eugenol, sesquiterpenes and the gallotannic acid. ${ }^{[16]}$

\section{Medicinal Property of Clove oil}

To Eliminates acne

They Kills parasites

\section{REFERENCES}

1. E. Kolaczkowska and P. Kubes, "Neutrophil recruitment and function in health and inflammation," Nature Reviews Immunology, 2013; 13(3):159-175.

2. J. Kodydkova, L. Vavrova, B. Stankova, J. Macasek, T. Krechler, and A. Zak, "Antioxidant status and oxidative stress markers in pancreatic cancer and chronic pancreatitis," Pancreas,2013; 42(4):614-621.

3. P. Rubiolo, B. Sgorbini, E. Liberto, C. Cordero, and C. Bicchi, "Essential oils and volatiles: sample preparation and analysis. A review," Flavour and Fragrance Journal, 2010; 25(5):282-290.

4. Rubiolo, P.; Sgorbini, B.; Liberto, E.; Cordero, C.; Bicchi, C. Essential oils and volatiles: sample preparation and analysis. Flavour Fragr. J. 2010; 25:282-290.

5. 2. Burt, S. Essential oils: their antibacterial properties and potential applications in foods - a review. Int. J. Food Microbiol. 2004; 94:223253

6. Sell, C.S. The Chemistry of Fragrance. From Perfumer to Consumer, 2nd ed.; The Royal Society of Chemistry: Cambridge, UK, 2006; 329.
To Improves blood circulation

To Reduces gum disease

To Boosts energy

They act as an Natural anti-inflammatory

They Kills molds and fungus.

\section{Turpentine oil}

Turpentine oil is made from the resin of certain pine trees. Turpentine oil is applied to the skin for joint pain, muscle pain, nerve pain, inflammation and toothaches.

\section{Camphor}

Camphor is a waxy consistency substance white or transparent solid having strong aroma. Its a terpenoid with the chemical formula $\mathrm{C}_{10} \mathrm{H}_{16} \mathrm{O}$. camphor is present in rosemary leaves belonging to family rosemary officinalis. Rosemary contain $10-20-\%$ of camphor its melting point is $175-177^{\circ} \mathrm{C}$

\section{Medicinal Benefits of camphor}

Readily absorbed through skin and produce coolness or warmth sensation.

Act as slight local anaesthetic and antimicrobial substance

\section{CONCLUSION}

The search for anti-inflammatory activities in essential oils has increased during last few years. This review suggests that essential oils and their major compounds have a potential for the treatment of inflammatory diseases especially in chronic inflammatory conditions. It is concluded that depending on the chemical composition of the essential oils, they can act as anti-inflammatory affecting the arachidonic metabolism or the cytokines production, or on the modulation of pro-inflammatory gene expression. Topical applications of plant oils may have different effect on the skin according to their composition and the pathophysiological context of the skin. However, numerous investigations should be carried out on their mode of action and their probable toxicological effects in order to optimize their potential uses for inflammatory diseases.

7. Maruyama, N.; Sekimoto, N.; Ishibashi, H. Suppression of neutrophil accumulation in mice by cutaneous application of geranium essential oil. J. Inflamm. 2005; 2:1-11.

8. Kamatou, G.P.P.; Viljoen, A.M. A review of the application and pharmacological properties of $\alpha$ - bisabolol and $\alpha$-bisabolol-rich oils. J. Am. Oil Chem. Soc. 2010; 87: 1-7.

9. Darsham, S.; Doreswamug, R. Patented anti-inflammatory plant drug development from traditional medicine. Phytother. Res. 2004; 18:343357.

10. Nasopoulou, C.; Karantonis, H.C.; Detopoulou, M.; Demopoulos, C.A.; Zabetakis, I. Exploiting the anti-inflammatory properties of olive (Olea europaea) in the sustainable production of functional food and neutraceuticals. Phytochem. Rev. 2014; 13:445-458.

11. Hillis WE. Polyphenols in the leaves of eucalyptus: a chemotaxonomic survey-II.: the sections renantheroideae and renantherae. Phytochemistry, 1967; 6:259-74.

12. Mulyaningsih S, Sporer F, Reichling J, Wink M. Antibacterial activity of essential oils from eucalyptus and of related components against multi-resistant bacterial pathogens. Pharm Biol, 2011; 49:893-9. 
13. Sadlon AE, Lamson DW. Immunemodifying and antimicrobial effects of eucalyptus oil and simple inhalation devices. Altern Med Rev 2010; 15:33-47.

14. Peana At, D'aquila Ps, Panin F, Serra G, Pippia P And Moretti Md. Anti-inflammatory activity of linalool and linalyl acetate constituents of essential oils. Phytomedicine.2002; 9:721-726.
15. Kim Hm and Cho Sh.Lavender oil inhibits immediatetype allergic reaction in mice and rats. J Pharm Pharmacol.1999; 51:221-226.

16. Schmuth, M.; Blunder, S.; Dubrac, S.; Gruber, R.; MoosbruggerMartinz, V. Epidermal barrier in hereditaryichthyoses, atopic dermatitis, and psoriasis. J. Dtsch. Dermatol. Ges. 2015; 13:11191123.

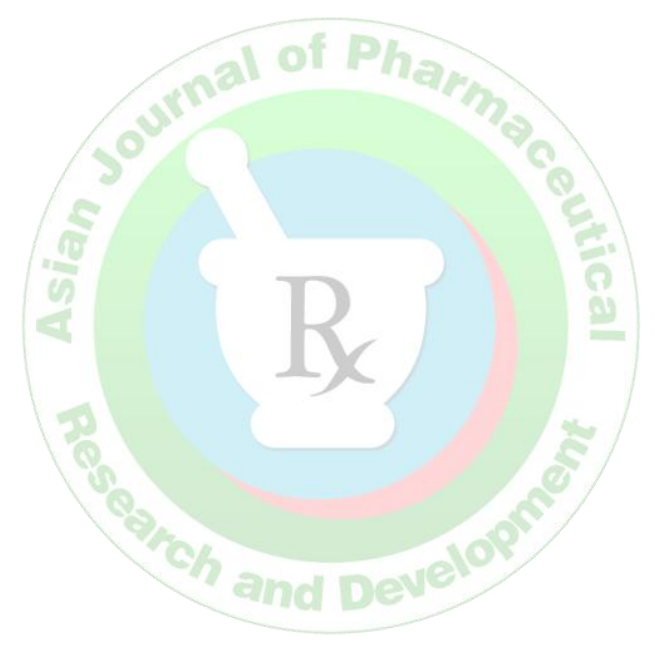

